\title{
DOSSIÊ
}

\section{Sociologia Política na Alemanha desde os anos de 1990 - desenvolvimento da subdisciplina e problemas atuais}

\section{Resumo}

O desenvolvimento da sociologia política alemã ao longo do século XX é tão complexo quanto a própria história da Alemanha. Em sua fase entre o nacional-socialismo e o 'socialismo real' a sociologia política já foi bem analisada (Nedelmann, 1997). No presente artigo, concentramo-nos, sobretudo, no seu desenvolvimento ao longo das últimas três décadas. Desde o fim dos anos de 1980, uma nova fase de profissionalização da sociologia política pôde ser observada. A fim de entender a situação atual da disciplina na Alemanha, analisamos o tema em cinco seções. No início do presente artigo, apresentamos um breve panorama histórico sobre a formação da sociologia política na Alemanha desde 1945. Depois, desloca-se o foco para desenvolvimentos recentes da disciplina, desde o fim dos anos de 1980 - só então a sociologia política ganhou um departamento independente na Sociedade Alemã de Sociologia e na Associação Alemã de Ciência Política. Após isso, faz-se uma revisão analítica da situação da sociologia política em universidades alemãs, de seus campos de trabalho, seus departamentos, seus cursos e suas prioridades de pesquisa. A partir disso, pode-se demonstrar que, embora seus tópicos abranjam muitas áreas da sociologia e da ciência política, a sociologia política não logrou tornar-se uma disciplina no sistema universitário. Em uma breve digressão, nos voltamos à administração pública como tópico de pesquisa para a sociologia política. Por fim, discutem-se conclusões sobre a sociologia política na Alemanha.

Palavras-chave: Sociologia política alemã. Ciência política. Interdisciplinaridade.

*Universidade de Ciências Sociais Aplicadas à Administração Pública e Privada da Renânia do Norte - Vestfália em Bielefeld e Colônia (Alemanha)

** Universidade de Ciências Sociais Aplicadas à Administração Pública e Privada da Renânia do Norte - Vestfália em Bielefeld e Colônia (Alemanha) 


\title{
Political Sociology in Germany since the 1990s - Development of the Sub-discipline and Current Issues
}

\begin{abstract}
The development of German political sociology in the 20th century is as complex as the history of Germany itself. Political sociology in the phase "between national socialism and real socialism" has well been analyzed (Nedelmann, 1997). In this article we will therefore primarily focus on its development over the past three decades. Since the end of the 1980s a new phase of professionalization of political sociology can be observed. In order to understand the current situation of political sociology in Germany we will analyze the subject in five sections. The article will at first give a brief historical overview about the formation of political sociology in Germany since 1945. The focus will then be set on recent developments of political sociology since the end of the 1980s. Only then political sociology became an independent section in the German Sociological Association and the German Association of Political Sciences. Third, the field will be analyzed by reviewing the situation of political sociology at German universities, their fields of work, their faculties, their courses and research priorities. It can be shown that the topics of political sociology reach out into many areas of sociology and political science, but that political sociology has not become a discipline by itself in the university system. In a brief excursus we will look into public administration as a research topic of political sociology. Finally conclusions on political sociology in Germany will be discussed.
\end{abstract}

Keywords: German political sociology. Political Science. Interdisciplinarity.

\footnotetext{
- Tradução: Eduardo Lara de Carvalho. Revisão técnica: Gerson Roberto Neumann Tradução do original em língua alemã
} 
Sociologias, Porto Alegre, ano 17, no 38, jan/abr 2015, p. 64-91

\section{Introdução}

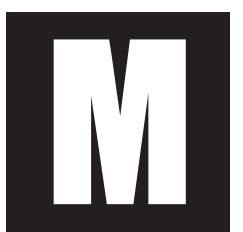

uitas vezes associou-se à sociologia política a concepção de "ciência da crise" (Ebbighausen, 1981). Por um lado, essa designação explica o seu surgimento enquanto subdisciplina na Alemanha; por outro, descreve uma função e um desafio que são centrais para a sociologia política atualmente, definindo-a como uma ciência que acompanha revoluções e crises.

Em meados do século XIX, começam a surgir questionamentos, reforçados pelas mudanças sociais das revoluções de 1848/49, os quais seriam retomados mais tarde pela sociologia política e marcariam o desenvolvimento da subdisciplina. A diferenciação gradual de um sistema econômico capitalista coloca em pauta as inter-relações entre o poder estatal e a sociedade de classes. Mais tarde, as análises de Karl Marx e dos representantes posteriores do Marxismo podem ser tidas como as origens definidoras de uma sociologia política moderna na Alemanha. Em especial, as análises conduzidas por Max Weber sobre as relações entre sociedade e Estado tornaram-se fundamentais (Stammer; Weingart, 1972, p. 15).

A conformação da sociologia política na Alemanha do século XX é descrita de maneira aguçada por Nedelmann (1997) em sua análise histórica. Enquanto as grandes crises do século XX parecem chegar ao fim com a dissolução da União Soviética e a reunificação da Alemanha, a sociologia política, enquanto ciência da crise, cai ela própria em crise na Alemanha (Giesen, 1989). Isso repercute na forma de um debate, no jornal semanal Die Zeit, sobre o papel da sociologia (Wozu heute noch Soziologie? ou "Para quê serve hoje a sociologia?") o qual recebe grande atenção da opinião pública ${ }^{1}$. Paralelamente a isso, a sociologia política na

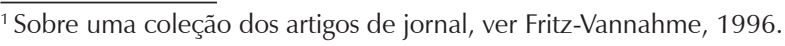


Sociologias, Porto Alegre, ano 17, no 38, jan/abr 2015, p. 64-91

Alemanha, questionada na sua essência, tenta se consolidar institucionalmente através da formação de um departamento próprio na Sociedade Alemã de Sociologia (SAS; em alemão, Deutsche Gesellschaft für Soziologie, DGS), em 1993. Na Associação Alemã de Ciência Política (AACP; em alemão, Deutsche Vereinigung für Politische Wissenschaft, DVPW), um departamento de sociologia política fora fundado já em 1986, também por causa de uma crise na ciência política. Ainda é incerto se as crises do século XXI, a começar pelas crises bancária e econômica que tiveram início em 2008, vão reanimar o interesse pela sociologia política.

Para analisar a posição atual da sociologia política na Alemanha, iniciamos retraçando o desenvolvimento da disciplina no século XXI, e, em seguida, tratamos da sociologia política no sistema universitário da Alemanha. Para isso, abordaremos a sociologia política fundamentalmente por uma perspectiva sociológica, ao mesmo tempo sem deixar de tratar da comunidade científica da ciência política. Além de uma avaliação sistemática da literatura científica, servem de base para o artigo os programas do Departamento de Sociologia Política da SAS, dos anos 1994 e 2006, bem como entrevistas com especialistas representantes do departamento correspondente na AACP, no qual não existem programas nem documentos similares. O presente artigo se divide nas seguintes partes:

Após uma curta retrospectiva sobre a sociologia política na Alemanha entre 1945 e 1989 (2), o foco desloca-se ao passado recente, especificamente ao desenvolvimento da disciplina após o fim dos anos de 1980 e início dos 1990 (3), quando foram fundados os departamentos de sociologia política na SAS e na AACP. Em seguida, analisaremos a sociologia política em relação à sua situação em universidades alemãs, a seus campos de trabalho, às suas ênfases de pesquisa e ao seu ensino (4). Por fim, enquanto representantes de uma faculdade de administração pública, pretendemos investigar a administração pública enquanto objeto da sociologia política na Alemanha (5). O artigo termina com (6) considerações finais. 
Sociologias, Porto Alegre, ano 17, no 38, jan/abr 2015, p. 64-91

\section{Sociologia Política na Alemanha a partir de 1945}

A sociologia política na Alemanha foi marcada, durante o século XX, pelas profundas crises políticas simbolizadas pelos anos de 1945, 1968 e 1989 - a queda do Reich alemão, o ápice dos movimentos estudantis e dos movimentos por direitos civis, e a queda do sistema da República Democrática Alemã, respectivamente. Nedelmann (1997) sugere uma tipologia para caracterizar a sociologia política desse período que consiste em quatro modos pelos quais sociólogos podem reagir à pressão do meio social e político:

(1) Profissionalização, isto é, a pressão é tratada estritamente por padrões científicos, e o meio político é, assim, definido como objeto da sociologia política. (2) Neutralização, isto é, o sociólogo escapa à pressão da situação política, ocupando-se primariamente com questões metodológicas ou se restringindo à coleta de dados. (3) Exit é a estratégia pela qual o sociólogo larga sua profissão definitivamente ou foge do país. (4) Politização acontece quando o sociólogo cede à pressão do meio e assume um papel político (Nedelmann, 1997, p. 158).

A fase de 1945 até o fim dos anos de 1950 é denominada por Nedelmann como fase de profissionalização inicial e neutralização (Nedelmann, 1997, p. 158). Até 1955, só havia catorze cátedras de sociologia na Alemanha; pode-se falar, portanto, de uma fase de pioneiros de uma sociologia do pós-guerra, como a chamou Lepsius (1983). Neste período, a sociologia foi reconstruída através de cientistas exilados que voltavam ao país, como Max Horkheimer (1895-1973), Theodor Wiesengrund Adorno (1903-1969) e Otto Stammer (1900-1978). A marca distintiva desta primeira fase após a guerra foi o fato de os sociólogos se ocuparem estritamente do presente, sem refletir sobre o nacional-socialismo.

Nedelmann designa a fase de 1960 a 1968 como fase de profissionalização, realizada pela segunda geração de sociólogos alemães. Dessa 
Sociologias, Porto Alegre, ano 17, no 38, jan/abr 2015, p. 64-91

geração faziam parte Ralf Dahren, Niklas Luhmann e Hans Paul Bahrdt, além de outros sociólogos, alguns dos quais haviam servido no exército durante a guerra quando jovens. Essa geração pode ser considerada uma comunidade de valores, na medida em que seus membros compartilhavam de uma crença profundamente enraizada no sistema democrático da República Federal da Alemanha. Nos anos de 1960 havia, além de Berlin, três outros centros da sociologia política: Tübingen, com o sociólogo Dahrendorf; Mannheim, com Lepsius; e Colônia, com Scheuch e Renate Mayntz, a única mulher de destaque na sociologia desse período. Esses sociólogos contribuíram com diferentes abordagens para a profissionalização, institucionalização e internacionalização da sociologia política na Alemanha².

Em decorrência dos movimentos estudantis, ocorreu, durante o período de 1968 a 1975, paralelamente à profissionalização, a politização da sociologia política. Influenciados pelas manifestações, os sociólogos que compunham a chamada "geração de 68 " formavam uma estrita comunidade de valores. Em virtude do enorme desenvolvimento da educação na Alemanha nesse período, sociólogos pertencentes à geração de 68 integraram o sistema universitário e ocuparam cátedras de sociologia. Assim, a sociologia política foi politizada e sua agenda de pesquisa se alterou. O debate sobre o neomarxismo se fazia marcadamente presente, o que ficou explícito pelo tema, escolhido por Adorno, da décima sexta conferência da Sociedade Alemã de Sociologia, em 1968: "Capitalismo tardio ou sociedade industrial". Um dos proeminentes representantes desse novo debate foi Claus Offe, que proveu um novo impulso à análise de classes com seu artigo "Dominação política e estruturas de classe" (Offe, Claus. Politische Herrschaft und Klassenstrukturen. 1969). Outra inovação na agenda de pesquisa que resultou dessa fase foi a investiga-

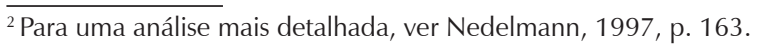


Sociologias, Porto Alegre, ano 17, no 38, jan/abr 2015, p. 64-91

ção sobre novos movimentos sociais, como resposta à emergência de um novo tipo de movimentos sociais nos anos de 1970.

A fase de 1975 até 1989 é classificada por Nedelmann (1997, p. 177 ss.) como uma fase de profissionalização e especialização. Enquanto desapareciam os últimos vestígios dos movimentos estudantis, a sociologia passava por um processo de especialização. O mercado acadêmico se tornou mais competitivo, e a concorrência entre sociólogos aumentou. Se antes os debates sociológicos ganhavam grande atenção pública, agora, a especialização causava uma queda no interesse público pela área.

Com o fim da República Democrática Alemã, em 1989, a sociologia sofreu uma grande perda de reputação. Os sociólogos alemães não puderam prever nem a queda geral do regime socialista nem o fim da RDA. Segundo Nedelmann (1997, p. 177), o "ponto de virada" de 1989 fez transparecerem três déficits severos na disciplina: a carência de investigação história sistemática sobre a queda de regimes políticos, a negligência de uma análise sociológica da RDA, e a desconsideração sistemática do nazismo enquanto campo de pesquisa legítimo da sociologia política.

Esse reconhecimento levou a um forte crescimento da pesquisa sociológica sobre a transformação de Estados socialistas em democracias (Joas; Kohli, 1993). Com a reunificação dos dois Estados alemães, surgiu um crescente interesse sobre identidade nacional, juntamente com os estudos de mudança de regime.

O crescimento do neo-nazismo e o aumento da violência contra minorias étnicas na Alemanha desde 1989 remete lamentavelmente ao déficit mencionado acima: a sociologia política não se orientou suficientemente para a análise histórica, e não lidou com o nazismo. Hoje, a geração mais nova de sociólogos conduz pesquisas nessa área (Bach, 1990; Sofsky, 1993). 
Sociologias, Porto Alegre, ano 17, no 38, jan/abr 2015, p. 64-91

\section{Desenvolvimentos recentes da sociologia política na Alemanha}

Seguindo a tipologia de Nedelmann (1997), na sociologia política a partir dos anos de 1990, é possível reconhecer, no princípio, uma fase de profissionalização em forma de institucionalização, marcada pela fundação de um departamento próprio na SAS. O departamento "Sociologia Política" da SAS foi fundado em 1993 como um dos 35 departamentos da instituição - uma fundação surpreendentemente tardia. A Sociedade Alemã de Sociologia foi fundada em 1909, com a participação de colaboradores que hoje estão entre os "clássicos" da sociologia, como Max Weber, o qual pode ser visto como um dos precursores da sociologia política.

O propósito da criação do Departamento foi concisamente explicitado em um programa (Departamento de Sociologia Política da SAS, 1994). O Departamento surgiu para servir de fórum onde, por um lado, debater-se-iam temas convencionais da sociologia política, como partidos políticos, constituições, instituições, eleições e opiniões políticas. Por outro lado, esse fórum buscava desconvencionalizar o conceito tradicional de política e fazer dele objeto de debate sociológico: foi citado como motivo para desenvolver uma sociologia da política

o fato de que política não corresponde nem se limita àquilo que fazem os agentes etiquetados como 'políticos'; não corresponde nem se limita ao que acontece em instituições e organizações definidas como 'políticas'; não corresponde nem se limita, enfim, àquilo que é encenado e difundido como 'processo político', e, portanto, não corresponde nem se limita àquilo que é 'administrado' disciplinarmente pela ciência política (Departamento de Sociologia Política da SAS, 1994, p. 1).

Esses objetivos constituem uma crítica à noção convencional do que seja política, baseada no que se considera política nas instituições e contextos decisórios tradicionais. Segundo esse entendimento, a política se 
Sociologias, Porto Alegre, ano 17, no 38, jan/abr 2015, p. 64-91

estenderia cada vez mais sobre os contextos da vida e da prática cotidianas. Com isso, é como se fosse criticada a compreensão de sociologia política dominante na AACP. A disciplina, segundo a moção para a fundação do Departamento da SAS, deveria ser adequadamente "ressociologizada" (Departamento de Sociologia Política da SAS, 1994). A AACP fundara o departamento equivalente já em 1986, como uma união de diferentes grupos de estudos sobre partidos políticos, associações, eleições e configurações, bem como política e comunicação. O propósito era consolidar o campo temático da sociologia política enquanto objeto de investigação dentro da associação. O departamento da AACP não estabeleceu um programa próprio de Sociologia Política, de modo que as motivações temáticas partem, como anteriormente, dos grupos de estudo individuais, enquanto o Departamento age como "guarda-chuva", como observou Alemann num congresso da AACP em 1997 (Alemann, 1998, p. 15). Segundo os entrevistados ${ }^{3}$, tiveram um papel norteador, em primeiro lugar, uma exposição mais clara da relação do social com o político e, em segundo, a necessidade de utilizar, para problematizações na ciência política, métodos sociológicos, especialmente abordagens quantitativas sobre campos de pesquisa, e assim levar em conta o desenvolvimento que estabeleceu também na Alemanha um conhecimento mais matemático e científico. Com isso, a perspectiva normativa da ciência política foi complementada com outra empírico-analítica.

\footnotetext{
${ }^{3}$ Os seguintes membros da AACP foram entrevistados a partir de diretrizes estruturadas para tal: Prof. Dr. Frank Marcinkowski, do Instituto de Ciências da Comunicação da Westfälische Wilhelms Universität Münster, membro do Departamento de Sociologia Política da AACP; Prof. Dr. Stefan Marshall, do Instituto de Ciências Sociais, Setor de Ciência Política da Heinrich Heine Universität Düsseldorf, porta-voz do Grupo de estudos de Política e Comunicação da AACP; Prof. Dr. Ulrich Rosar, do Instituto de Ciências Sociais, Setor de Sociologia da Heinrich Heine Universität Düsseldorf, porta-voz do Grupo de estudos de Eleições e Atitudes Políticas da AACP; Prof. Dr. Rudolf Speth, do Departamento de Ciências Sociais, especialista no Sistema Político da República Federal da Alemanha - Estado em Transição, da Universidade de Kassel, porta-voz do Grupo de estudos em Associações da AACP.
} 
Sociologias, Porto Alegre, ano 17, no 38, jan/abr 2015, p. 64-91

A fundação desses departamentos torna necessário perguntar qual é a essência da sociologia política. A concepção de sociologia política na Alemanha durante os anos de 1990, e mesmo até hoje, é vaga e controversa. Nesse contexto, uma série de discussões sobre a concepção da disciplina ocorreu desde 1990 (Nedelmann, 1997; Nedelmann, 1994; Alemann, 1998; Endruweit, 1998; Meuser, 2003; Nasseho e Schoer, 2003; Trotha, 2006; Trotha, 2010).

A fundação do departamento na SAS já começou com uma controvérsia a respeito do seu nome. Na moção de fundação, constava o nome "Sociologia da Política", mas a assembleia da Sociedade Alemã de Sociologia decidiu denominar o departamento de "Sociologia Política"4. Havia a preocupação de que, com esse título, pudesse ficar associada uma ideia de politização de uma área especializada da sociologia. Hitzler (1999, p. 55) argumenta que o título "sociologia política" "significa concretamente uma subordinação da sociologia aos princípios da política, e não uma análise crítica desses". Da parte da ciência política também houve críticas ao título; frisou-se, sobretudo, que o departamento deveria ser denominado de "Sociologia da Ciência Política". De maneira geral, o debate girou em torno da questão: a sociologia política é uma subdisciplina da sociologia, uma subdisciplina da ciência política ou um "guarda-chuva" que cobre parte das duas disciplinas? (Alemann, 1998).

Os anos seguintes presenciaram uma autoafirmação, feita através da delimitação das áreas de estudo da sociologia política e por meio da especificação de paradigmas teóricos. O departamento da SAS definiu áreas temáticas para demarcar o conteúdo e o objeto da sociologia política. No seu segundo programa (Departamento de Sociologia Política da SAS, 2006), a direção estimula uma revisão programática do Departamento, e apresenta à concepção o seguinte entendimento de política:

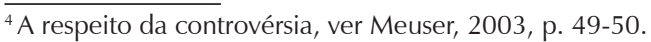


Sociologias, Porto Alegre, ano 17, no 38, jan/abr 2015, p. 64-91

'política' é o campo de ação social onde se disputa pela influência e pelo controle sobre decisões e processos decisórios institucionalizados e não institucionalizados, os quais concernem a interesses comuns de pessoas, às relações internas e externas de suas formas de associação e, sobretudo, à distribuição de poder (p. 1).

No que diz respeito à análise sociológica da política, o Departamento dá seis sugestões que devem servir a uma autoafirmação da sociologia política alemã. Elas não são sistematicamente delimitadas; antes, o entendimento do que constitui a sociologia política é entregue aos debates e às atividades de pesquisa dos seus membros. A seguir, uma síntese das sugestões do segundo programa (Departamento de Sociologia Política da SAS, 2006):

1) O departamento ressalta que, paralelamente aos processos de institucionalização de poder e autoridade, não se deve perder de vista os processos de desinstitucionalização.

2) As guerras são identificadas como uma área de estudos negligenciada até agora pela sociologia política (Joas, 1991) mas de central importância; guerras surgem junto com a formação e integração de sistemas políticos. O fato de a análise de guerras não ter ocupado um papel maior é explicado pelo fato de, na Europa dos Estados-nação, as guerras terem sido antes conflitos entre Estados do que questões sociais. No entanto, com guerras étnicas e religiosas, bem como com o terrorismo internacional, as guerras se tornaram uma realidade social e interna aos Estados. A religião também deve passar a ser investigada intensamente pela sociologia política, por ser constitutiva de sistemas políticos e, inclusive, por causa da carga religiosa presente em guerras. Uma peculiaridade da sociologia política na Alemanha é o fato de o envolvimento da Bundeswehr (as Forças Armadas da Alemanha) em ações no exterior ter desfeito um consenso geral entre os partidos políticos que durara quase meio século, o que foi descrito como uma mudança de paradigmas da política de defesa (Schwab-Trapp, 2002). 
Sociologias, Porto Alegre, ano 17, no 38, jan/abr 2015, p. 64-91

3) A institucionalização e desinstitucionalização de poder e autoridade devem ser examinadas sob o ponto de vista da representação política e da legitimidade política. O problema da representação não é resolvido através da equiparação entre representação e sistema representativo, tampouco, em âmbito institucional, através das instituições decisórias centrais. Antes, deve-se contemplar a questão da permanência de formas de representação e de legitimação políticas e a questão da invenção de formas alternativas. Mesmo nas democracias ocidentais, a mudança dos paradigmas institucionais da representação pode ser acompanhada sociologicamente. Entre os conceitos-chave estão incluídos a subculturalização da política, a corrupção política, e retorno da política de formação de elites. Nessa mudança, é tida como significativa a relação, marcada pela encenação nas mídias (de massa), entre representados e representantes. Visto dessa maneira, entre as tarefas centrais da sociologia política está a investigação da relação entre política e mídia (SAS, 2006, p. 3). O problema da legitimação política, desde o princípio da sociologia da dominação um problema constitutivo, ainda não foi devidamente examinado em vários aspectos, como, por exemplo, em relação à autolegitimação de governantes, bem como à legitimação de governantes através do setor administrativo, e através de especialistas e comunidades científicas - o que tem ganhado cada vez mais atenção nos meios científicos.

4) Nos processos de delimitação da política, cabe muita importância às organizações não governamentais (ONGs) e à subpolítica. O interesse de pesquisa por ONGs surgiu, principalmente, em função do papel de ONGs para os processos de democratização nos países pós-socialistas do Leste Europeu, bem como para políticas de desenvolvimento. Sob o conceito de subpolítica, entende-se a ação social pela qual indivíduos ou grupos se expressam politicamente sem se 
Sociologias, Porto Alegre, ano 17, no 38, jan/abr 2015, p. 64-91

utilizarem de instituições políticas nem tentarem influenciar intencionalmente os processos decisórios da política.

5) A sociologia política de língua alemã deve abrir seus questionamentos e propósitos para realidades políticas externas ao contexto europeu, e para os processos da globalização. Isso inclui, por exemplo, a análise empírica de ordens políticas transnacionais, de translocalidade e de espaços em processo de globalização, de regulamentos internacionais de conflito; do direito internacional e de criminalidade e controle de criminalidade transnacionais, assim como de regimes internacionais de migração e de refugiados. Para isso, não se pode perder de vista a crescente importância do local em sua inserção no processo da globalização.

6) Na essência de uma sociologia da política, reside a teoria empírico-analítica da ação social. Em nível metodológico, ela inclui todo o espectro da pesquisa social padronizada e não padronizada. É importante romper com a limitação da sociologia política às sociedades ocidentais contemporâneas. Sob as condições de um mundo globalizado, a sociologia política deve trabalhar com comparação intercultural e cooperar interdisciplinarmente, em especial com a ciência política, a etnologia política, e a historiografia.

Com esse esboço de conteúdo programático do Departamento de Sociologia Política condizem, em grande parte, algumas outras delimitações da sociologia política, o que não surpreende, já que estas foram elaboradas por membros do Departamento (Meuser, 2003; Trotha, 2006; Trotha, 2010). Também existem paralelos com os campos de pesquisa da sociologia política nomeados pelos representantes da AACP; no entanto, fica claro que, para esta, o nível microssociológico assume o ponto central do interesse de investigação, quando partidos políticos, associações, movimentos sociais, elites, comportamento eleitoral e comunicação política 
Sociologias, Porto Alegre, ano 17, no 38, jan/abr 2015, p. 64-91

são referidos como campos de pesquisa centrais da sociologia política. Além disso, os processos de globalização, de democratização e redemocratização, de europeização, e de desenvolvimento em direção ao Estado de bem-estar social são nomeados como objetos de pesquisa.

Meuser (2003) destaca ainda, além do citado, o estudo da mudança de regime ${ }^{5}$, bem como de políticas de gênero. Com o colapso do socialismo estatal, tem-se uma nova área de pesquisa na pauta da sociologia política, denominada de estudos de mudança de regime. Alguns temas importantes para essa área são a persistência de antigas estruturas, e a aceitação de estruturas democráticas. A Alemanha constitui uma exceção interessante para esta área, sendo o paralelismo de duas culturas políticas num único Estado especialmente interessante. O estudo de mudança de regime em Estados do Leste Europeu pode ganhar futuramente mais importância face aos acontecimentos atuais na Ucrânia.

A política de gênero, diz Meuser (2003), está surpreendentemente negligenciada pela sociologia política na Alemanha. Com isso, deve ser sua intenção apontar que esse campo de pesquisa não tem sido explorado pela comunidade científica dos sociólogos políticos. Institucionalmente, os estudos da mulher e de gênero estão presentes em outros departamentos, mas pela perspectiva analítica poderiam ser perfeitamente designados, em certos aspectos, como questões de sociologia política. Questionamentos científicos relevantes se encontram tanto em políticas de igualdade de gênero institucionalizadas como nas subpolíticas de relacionamentos e interações hetero e homossociais

As referidas delimitações da disciplina baseadas em conteúdos temáticos já receberam críticas. Bach (2004) aponta, com razão, que uma subdisciplina não pode ser definida por uma listagem de temas que a

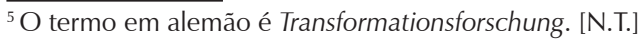


Sociologias, Porto Alegre, ano 17, no 38, jan/abr 2015, p. 64-91

determinam primariamente através de interesses de pesquisa individuais dos membros dos departamentos. Bach sugere, em vez disso, definir a disciplina por meio do paradigma sociológico da dominação. Segundo o autor, o conceito de dominação é semanticamente antiquado, se comparado a conceitos como direção política, governança, e redes políticas, mas mesmo assim permanece tendo grande importância para a sociologia política. Como base teórica, Bach aponta as concepções fundamentais de Georg Simmels e Max Weber, bem como as teorias da elite, as teorias de desigualdade social, o entendimento sistemático-teórico da política enquanto tomada de decisões de coesão coletiva, e as recentes análises sociológicas de instituições (Bach, 2004, p. 20).

Embora se justifique a crítica de Bach a uma orientação da sociologia política baseada exclusivamente em temas, ele não percebe que uma delimitação temática, como a de Meuser (2003), busca demarcar a sociologia política dentro da sociologia, para estruturar a disciplina e suas subdisciplinas. Bach - com sua abordagem teorética-paradigmática - se propõe a destacar especificamente o caráter sociológico da sociologia política, em oposição à ciência política.

A seguir, a situação da sociologia política será examinada mais a fundo, à luz de cátedras, currículos e ênfases de pesquisa em universidades alemãs.

\section{A sociologia política no sistema universitário da Alemanha}

\subsection{Cátedras}

Cátedras que levam o nome "Sociologia Política" em universidades alemãs existem apenas em poucas faculdades ${ }^{6}$. A sociologia política é ${ }^{6}$ Segundo o resultado de uma análise sistemática a partir das entrevistas com especialistas e
dos sites das universidades. 
Sociologias, Porto Alegre, ano 17, no 38, jan/abr 2015, p. 64-91

mais frequentemente ensinada em cátedras de sociologia ou de ciência política, como um campo temático entre outros. As poucas cátedras de sociologia política são, via de regra, associadas aos institutos de ciência política, e se concentram em áreas específicas da sociologia política, como o estudo de partidos políticos, eleições e configurações. Isso se dá, por um lado, por motivos temáticos, por outro por motivos financeiros.

É bastante significativo que, no meio sociológico e em institutos de sociologia, a sociologia política seja contemplada, no âmbito das cinco áreas principais da sociologia (microssociologia, macrossociologia, estrutura social, metodologia, teoria sociológica), como uma "sociologia especializada". Por outro lado, na perspectiva da ciência política, a sociologia política representa uma área adicional, que complementa apropriadamente as cinco áreas principais da ciência política (teoria política, sistemas políticos, política comparada, análise política, metodologia), o que fica claro pelo panorama das cátedras. $\mathrm{A}$ isso se somam fatores financeiros: por conta da má situação econômica de vários estados que são responsáveis pela política educacional na Alemanha, nos últimos anos quase não se criaram novas cátedras na área de ciências sociais.

Atualmente existem as seguintes cátedras com a denominação "Sociologia Política" (Politische Soziologie) na Alemanha:

- Cátedra de Sociologia Política na Universidade de Bamberg. A cátedra está vinculada à área de ciência política, e é complementada por outras cátedras: Relações Internacionais, Ciência Política Empírica, Teoria Política, Integração Europeia, Análise Política Comparada e Política Comparada. A titular da cátedra na Universidade de Bamberg é Simone Abendschön. As ênfases de pesquisa ficam no âmbito das configurações políticas e do comportamento político a partir de uma perspectiva comparada internacional, bem como no âmbito dos métodos de pesquisa social empírica. ${ }^{7}$

\footnotetext{
${ }^{7}$ http://www.uni-bamberg.de/polsoz/lehrstuhlteam/prof-dr-simone-abenschoen/ . Acesso em 07/10/2014. O titular da cátedra já não é o mesmo da data de publicação original do presente texto. O link trazido aqui foi atualizado. [N.T.]
} 
Sociologias, Porto Alegre, ano 17, no 38, jan/abr 2015, p. 64-91

- Cátedra de Ciência Política com Ênfase em Sociologia Política e Teoria do Estado na Goethe Universität Frankfurt am Main. "A cátedra se dedica ao ensino e pesquisa em temas de sociologia política, através de uma perspectiva internacional e comparada" ${ }^{\prime \prime}$, sendo que, na pesquisa, a ênfase é dada ao estudo da democracia (profissionalização da política, padrões de carreira política, noções de democracia de agentes políticos) e ao Estado, em particular ao entendimento do Estado de bem-estar social e do Estado repressor. A ênfase regional se direciona ao Leste Europeu e às Américas do Sul e do Norte. O catedrático é Jens Borchert.

- Cátedra de Ciência Política I: Sociologia Política, na Universidade de Mannheim. "No centro da pesquisa fundadora da cátedra estão configurações políticas e comportamento político, em particular o comportamento eleitoral dos cidadãos de democracias modernas. A abordagem para tal é microanalítica - sem que os cidadãos sejam contemplados isoladamente. A característica da pesquisa é acima de tudo a tentativa de inserir cidadãos individuais em contextos diversos. [...] Questões da comunicação política (acerca do papel das mídias de massa ou das campanhas eleitorais, por exemplo) estão, assim, sob o foco da pesquisa (e do ensino) da cátedra, assim como questões da psicologia política" ${ }^{\prime \prime}$. O catedrático é Rüdiger Schmitt-Beck. A cátedra da Universidade de Mannheim foi citada por todos os entrevistados como um padrão para a sociologia política na Alemanha.

A estrutura do Instituto de Ciência Política da Leibniz Universität Hannover é dividida de acordo com as áreas principais da ciência política. A sociologia política representa uma área de trabalho do Instituto de Ciência Política. "Para isso, os(as) cientistas que trabalham na área de ensino dedicam atenção especial para a ação e o funcionamento de organizações intermediárias, como partidos políticos, sindicatos, e associações, bem como para

${ }^{8}$ http://www.fb03.uni-frankfurt.de/49136168/Profil . Acesso em 07/10/2014.

${ }^{9}$ http://www2.sowi.uni-mannheim.de/lspol1/?page_id=107 . Acesso em 07/10/2014. 
Sociologias, Porto Alegre, ano 17, no 38, jan/abr 2015, p. 64-91

movimentos sociais antigos e novos. Em virtude da atribuição e legitimação de poder político em democracias parlamentares representativas se dar, de fato, através de eleições, o estudo empírico das eleições constitui uma ênfase importante da área do ensino. Outra ênfase da sociologia política em Hannover é formada pelo estudo empírico de concepções e valores"10.

Essa seleção formal de cátedras cujas denominações incluem explicitamente "sociologia política" evidentemente não representa a totalidade das atividades em sociologia política na Alemanha. Assim, a pesquisa no âmbito da sociologia política é praticada em diferentes universidades e instituições no país. Para citar algumas, há a Universidade de Dortmund (Ronald Hitzler, Michael Meuser), a Universidade de Bielefeld (Klaus Peter Japp, Boris Holzer), a Universidade de Munique (Ulrich Beck, Armin Nassehi), o Centro para Resolução de Conflitos da Universidade de Marburg (Zentrum für Konfliktforschung) e o Instituto de Pesquisas Interdisciplinares sobre Conflito e Violência, da Universidade de Bielefeld, e pesquisadores individuais na Universidade de Passau (Maurizio Bach) e na Universidade de Wuppertal (Peter Imbusch), os quais desenvolvem pesquisa sobre questões político-sociológicas. Essa lista é uma mera amostra, e poderia ser estendida. Todavia, a seleção a partir das denominações citada acima demonstra que a sociologia política no sistema de ensino superior alemão e no âmbito da sociologia é tida como secundária.

\subsection{Cursos e currículos}

Entre os cursos de bacharelado na Alemanha, predominam os de orientação de ciência política ou sociológica e, via de regra, devem ensinar os fundamentos das respectivas disciplinas científicas, como os cursos de sociologia das universidades de Darmstadt, Düsseldorf, Duisburg-

\footnotetext{
${ }^{10} \mathrm{http}: / /$ www.ipw.uni-hannover.de/pol_soziologie.html . Acesso em 07/10/2014.
} 
Sociologias, Porto Alegre, ano 17, no 38, jan/abr 2015, p. 64-91

-Essen, Frankfurt am Main, Mannheim e Munique, e os cursos de ciência política das universidades Duisburg-Essen, Freien Universität Berlin e Universidade de Mannheim. ${ }^{11}$

Além desses, existem cursos de bacharelado em algumas instituições superiores, nos quais são ensinados em conjunto conteúdos didáticos de sociologia e de ciência política. Alguns bons exemplos são os diferentes bacharelados em "Política e Sociedade", no Instituto de Ciência Política e Sociologia da Universidade de Bonn, o bacharelado integrado "Ciências Sociais - Mídia, Política, Sociedade", na Heinrich Heine Universität Düsseldorf, e o curso de bacharelado "Ciência Política e Sociologia", da Martin-Luther-Universität-Halle-Wittenberg ${ }^{12}$. Ainda, na cátedra de sociologia política no bacharelado em ciência política da Universidade de Bamberg, são ensinadas metodologias e temas da sociologia política como parte do módulo básico ${ }^{13}$.

A especialização costuma ser feita em cursos de mestrado. Entre estes, existem, além de cursos "puros" de sociologia ou de ciência política, uma infinidade de diferentes cursos oferecidos, entre os quais há, também, alguns que podem ser classificados na área da sociologia política. A Universidade de Bonn, por exemplo, oferece um curso de mestrado em "Sociedades, Globalização e Desenvolvimento"14; a Goethe Universität Frankfurt am Main, um mestrado em "Estudos internacionais / Estudos sobre paz e conflito"15; e a Heinrich Heine Universität Düsseldorf, um "Mestrado em Ciências Sociais: Estruturas Sociais e Governo Global". O

\footnotetext{
$\overline{{ }^{11} \mathrm{http}: / / w w w . s t u d i e r e n-s t u d i u m . c o m / s t u d i u m / S o z i o l o g i e ~ . ~ A c e s s o ~ e m ~ 11 / 10 / 2014 . ~}$

${ }^{12} \mathrm{http}$ //www.uni-duesseldorf.de/home/studium-und-lehre-an-der-hhu/studium/alle-studiengaenge-von-a-z/studiengang-informationen/studiengaenge/sozialwissenschaften-medien-politik-gesellschaft.html. Acesso em 11/10/2014; http://www.soziologie.uni-halle.de/studium/ modulhandbuecher-ba.html\#a1. Acesso em 11/10/2014.

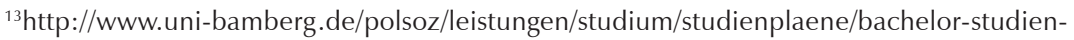
gang-gemaess-studien-und-pruefungsordnung-vom-01042012/. Acesso em 11/10/2014.

14 http://www.politik-soziologie.uni-bonn.de/studium/angebotene-studiengaenge/ma-gesellschaften-globalisierung-und-entwicklung . Acesso em 11/10/2014.

${ }^{15}$ http://www.fb03.uni-frankfurt.de/44397526/download . Acesso em 11/10/2014.
} 
Sociologias, Porto Alegre, ano 17, no 38, jan/abr 2015, p. 64-91

curso integrado da Faculdade de Filosofia da Universidade de Düsseldorf tem como objetivo prover ao aluno "um profundo conhecimento sobre a dinâmica da mudança social, sobre a cobrança por uma forma de governar moderna e democrática, assim como sobre a intermediação midiática da política. É dada uma ênfase especial às cobranças que acarretam mudanças sócio-estruturais, desnacionalização, e governança em prol da estabilidade e do desenvolvimento de democracias"16.

Por fim, seguem existindo cursos que concedem diploma ${ }^{17}$. Na Technische Universität Dresden, por exemplo, pode-se cursar um Diplomstudium (curso que concede diploma) em sociologia. ${ }^{18}$ No site da cátedra de Sociologia de Armin Nassehi, na Ludwig Maximilians Universität München, aponta-se que o curso concede um diploma, e são explicitadas duas funções principais da cátedra: "em primeiro lugar, ela é responsável pela formação teórica no curso de Sociologia; em segundo, oferece uma possibilidade de ensino continuado para áreas de aprofundamento, como a sociologia da cultura, a sociologia política, a sociologia do conhecimento e a sociologia da ciência. O ensino da cátedra se compromete com o princípio de romper com as já estabelecidas diferenciações condutoras na prática sociológica. As linhas divisórias entre sociologia geral e especializada, entre sociologia teórica e empírica, e também entre paradigmas quantitativos e qualitativos sugerem uma organização mais contingente em sua estrutura do que a sistematização científica normal de nossa profissão nos levaria a pensar"19.

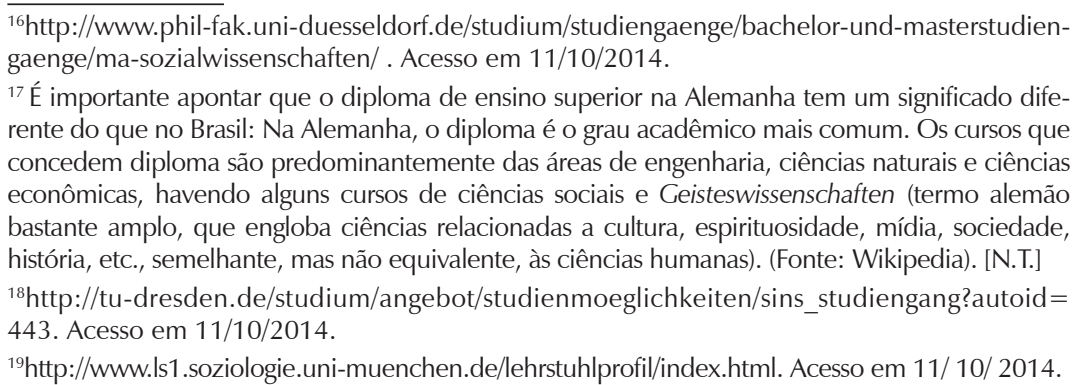


Sociologias, Porto Alegre, ano 17, no 38, jan/abr 2015, p. 64-91

\subsection{Pesquisa}

As áreas principais da pesquisa na área da sociologia política na Alemanha já se tornaram claras com a visão geral sobre o programa do Departamento de Sociologia Política da SAS e sobre as cátedras até aqui exposta. Dessas áreas principais, pode-se dizer, tomando-se por base o objeto de estudo da sociologia política, que elas se movimentam na interface da sociologia com a ciência política, e podem ser enquadradas da seguinte forma: no nível microssociológico, ocupam o centro do interesse de pesquisa: partidos; sindicatos e associações; novos movimentos sociais e organizações não governamentais; eleições e comportamento eleitoral; estudos do comportamento, atitude e comunicação políticas. No nível macrossociológico, são discutidos: processos de institucionalização e de desinstitucionalização do poder; ordens políticas, incluindo suas mudanças em função de guerra e religião; o desenvolvimento de estados de bem-estar social, bem como a representação e legitimação do poder político.

Atualmente, o estudo de partidos políticos, eleições e comportamento eleitoral tem tido papel de destaque nas faculdades alemãs, segundo os entrevistados. Isso se dá, entre outros fatores, pelas mudanças no sistema partidário na Alemanha e na Europa. Tais mudanças se expressam, por um lado, pelo surgimento de novos partidos na Alemanha, como o Partido Pirata da Alemanha (Piratenpartei Deutschland), que defende a autodeterminação informativa e que participa, há alguns anos, de diversos parlamentos estaduais e locais, ou o partido eurocético Alternativa para a Alemanha (Partei Alternative für Deutschland, ou AfD), que ficou de fora do parlamento alemão em 2013 em função da cláusula dos cinco por cento (segundo a qual somente os partidos políticos que obtêm ao menos cinco por cento dos votos válidos ou três mandatos diretos podem obter representação parlamentar), mas que desde maio de 2014 é representado por sete membros no Parlamento Europeu. Por outro lado, mu- 
Sociologias, Porto Alegre, ano 17, no 38, jan/abr 2015, p. 64-91

danças no sistema partidário podem ser observadas no fato de o Partido Democrático Liberal Alemão (Freie Demokratische Partei, ou FDP), representado desde o período pós-guerra no Bundestag (o parlamento nacional alemão), não ter representantes eleitos para esse órgão na última eleição. Além disso, diversos países europeus viram partidos conservadores de direita alcançar um enorme número de votos, como a Front National (FN) na França, que foi eleita por mais de um quarto do eleitorado francês. Nesse contexto, o partido AfD, membro dos Reformistas e Conservadores Europeus (ECR), também é visto de forma crítica.

No que se refere ao estudo de partidos políticos, dois grandes estudos, feitos nos últimos anos, merecem destaque ao se falar de sociologia política na República Federal da Alemanha: o Estudo de Membros Partidários da Alemanha, de 2009, e o Estudo Eleitoral Nacional da Alemanha.

O Estudo de Membros Partidários da Alemanha (em alemão, deutsche Parteimitgliederstudie), de 2009, foi realizado pelo Instituto de Estudos em Direito Partidário e em Partidos Políticos Alemães e Europeus (em alemão, Institut für deutsches und europäisches Parteienrecht und Parteienforschung, ou PRuF) da Heinrich Heine Universität Düsseldorf e pelo Departamento de Sociologia Política da Leibniz Universität Hannover. O objeto do estudo foi "a composição sócio-estrutural, psicográfica e profissional de membros de partidos alemães, bem como os motivos para a adesão ao partido, para atividades intrapartidárias e para a saída do partido. Empreendido como replicação parcial do Estudo de Membros Partidários de Potsdam (Potsdamer Parteimitgliederstudie), do ano de 1998, o estudo dá ênfase especial ao momento dinâmico de mudança no decorrer de uma década, assim como aos efeitos desse momento sobre o desenvolvimento da democracia partidária no país" 20 .

$\overline{{ }^{20} \mathrm{http}: / / w w w . p h i l-f a k}$.uni-duesseldorf.de/pw-alemann/forschungsprojekte/pamis2009/. Acesso em 20/10/2014. 
Sociologias, Porto Alegre, ano 17, no 38, jan/abr 2015, p. 64-91

O Estudo Eleitoral Nacional da Alemanha (em alemão, Deutsche Nationale Wahlstudie; em inglês, German Longitudinal Election Study, GLES) é tido como atual "porta-estandarte" da sociologia política. O estudo se propõe a examinar as eleições de 2009, 2013 e 2017 do Parlamento Alemão, tendo em vista "como o eleitorado reage a novos cenários complexos da política eleitoral" 21 . O trabalho de pesquisa é realizado em uma cooperação entre as universidades de Frankfurt am Main e Mannheim e o Centro Científico de Pesquisa Social de Berlin, um instituto de pesquisa extrauniversitário.

Ademais, as questões da comunicação e participação política têm recebido mais atenção, sobretudo pelo viés das mídias novas e das mídias sociais. No entanto, muitas vezes, grandes projetos de pesquisa nessa área não estão associados a cátedras de sociologia política, mas a outras. Como exemplo, há o Instituto de Ciências da Comunicação da Westfälische Wilhelms Universität, em Münster, cujo site destaca que a estrutura de pesquisa é essencialmente definida pelas áreas de trabalho dos professores. Entre as ênfases de pesquisa estão o desenvolvimento de mídias e da democracia (estabilidade e mudança de instituições democráticas; temas midiáticos e o conhecimento político; estruturas midiáticas compatíveis à democracia), a teoria da "midiatização" de subsistemas sociais (política, ciência, esporte), a midiatização do cotidiano e da sociedade, etc. ${ }^{22}$

Há, ainda, o "Programa Avançado em Participação Online" (Fortschrittskolleg Online-Partizipation) do estado alemão de Nordrhein-Westfalen, coordenado pelo professor da cátedra de Redes Informáticas e Sistemas de Comunicação da Heinrich Heine Universität. No programa, uma equipe interdisciplinar de professores e professoras da Universidade de Düsseldorf e da Faculdade de Administração Pública do estado de Nordrhein-Westfalen, incluindo sociólogos e cientistas políticos, deve investigar temas, os quais podem ser associados ao campo de estudo da

\footnotetext{
$\overline{{ }^{21} \mathrm{http}: / / g l e s . e u / w o r d p r e s s / ~ . ~ A c e s s o ~ e m ~ 20 / 10 / 2014 . ~ P a ́ g i n a ~ d i s p o n i ́ v e l ~ e m ~ i n g l e ̂ s . ~}$

${ }^{22}$ http://www.uni-muenster.de/Kowi/forschen/nach-personen.html . Acesso em 20/10/2014.
} 
Sociologias, Porto Alegre, ano 17, no 38, jan/abr 2015, p. 64-91

sociologia política. O questionamento central do projeto é: "como e sob quais condições pode-se desenvolver sistematicamente, aplicar, e avaliar cientificamente o potencial da participação online a nível comunitário?". ${ }^{23}$

\section{A administração pública como objeto da sociologia política na Alemanha}

Atualmente, a administração pública não constitui, na Alemanha, um objeto de investigação central para a sociologia política. Isso pode ser atribuído, em primeiro lugar, ao fato de política e administração serem entendidos como dois subsistemas diferentes, que funcionam de acordo com lógicas distintas - apesar da convicção de que a política é realizada através da administração, e de que a administração é, em muitos aspectos, politizada. Em segundo lugar, cabe mencionar a problemática da "acessibilidade da área", sobretudo na área política, que é tida como difícil e, portanto, vista de maneira crítica sob a perspectiva científica, pois parece não buscar resultados objetivos.

A pesquisa em administração pública, na Alemanha, é marcada por ser fortemente voltada a uma perspectiva interna da administração, e é tratada nas universidades, via de regra, nas cátedras sobre ciência da administração. Estas podem se orientar tanto pela ciência política quanto pela jurisprudência como, por exemplo, as cátedras de "Administração Comparada e Análise de Políticas Públicas", de "Ciência da Administração e Direito Público", de "Direito Constitucional, Direito Administrativo e Direito da União Europeia" e de "Administração Comparada com ênfase na Administração na Europa" na Universidade Alemã de Ciências da

\footnotetext{
${ }^{23}$ http://www.uni-duesseldorf.de/home/startseite/news-detailansicht/article/nrw-fortschrittskolleg-online-partizipation-wird-mit-26-millionen-euro-gefoerdert.html?cHash =d151f7f2e9c08 7dbd46d6e1cd6cbf333. Acesso em 20/10/2014. Página disponível em inglês.
} 
Sociologias, Porto Alegre, ano 17, no 38, jan/abr 2015, p. 64-91

Administração, em Speyer, ou as cátedras com relações científico-administrativas nas universidades de Constança e Friedrichshafen ${ }^{24}$.

No âmbito do debate internacional da Nova Gestão Pública, nos anos de 1990, foram discutidas, na pesquisa e na literatura em ciências administrativas na Alemanha, sobretudo abordagens para a reforma interna da administração. Nesse contexto, sob a bandeira do Neues Steuerungsmodell (Novo Modelo de Gestão da Alemanha), métodos e instrumentos de gestão de empresas, como a gestão da qualidade, a descentralização do gerenciamento de recursos, a gestão de recursos humanos, etc. foram transpostos para a administração pública, sem receberem um embasamento teórico apropriado (Bogumil et. al., 2007).

O debate acerca do conceito de governança foi complementado a partir de meados dos anos de 1990, com a promessa de uma nova forma de controle da ação pública para os diversos atores estatais e não estatais envolvidos nos processos de formulação e de implementação de políticas (Klenk; Nullmeier, 2004; Benz; Doze, 2010). Com isso, um reajuste da relação entre administração, política e cidadania e da interação entre estas toma um papel central, de modo a fortalecer o papel dos cidadãos. Esse redirecionamento tem como modelo a "sociedade civil". O desenvolvimento foi discutido também sob o termo de "Democracia Cooperativa" (Holtkamp, Bogumil, Kißler, 2006).

\section{Conclusões}

A sociologia política na Alemanha foi marcada por grandes crises e revoluções políticas durante o século XX, o que determinou os seus campos de investigação e seu direcionamento profissional e político. Desde os anos de

\footnotetext{
${ }^{24}$ http://www.dhv-speyer.de/Studium/Lehrstuehle.htm,http://www.polver.uni-konstanz.de/ professuren-ags/, e https:/www.zu.de/forschung-themen/uebersicht-lehrstuehle-institute.php. Acessos em 20/10/2014.
} 
Sociologias, Porto Alegre, ano 17, no 38, jan/abr 2015, p. 64-91

1990, a sociologia política voltou a se institucionalizar com mais força dentro da sociologia, e estabeleceu um departamento próprio dentro da SAS. Um processo semelhante se realizou no fim dos anos de 1980 na AACP.

Seguindo-se a análise de Nedelmann (1997), pode-se chamar o desenvolvimento atual como uma fase de profissionalização. Sociólogos políticos reagem, assim, a uma crise que a sociologia política vive desde a queda da RDA e de outros estados socialistas. A subdisciplina foi questionada por, até 1989, não incluir entre os seus objetos de investigação os processos de transformação dos regimes socialistas. Surpreendida por grandes mudanças sociais, a sociologia política na Alemanha não se recuperou até hoje do debate público acerca da função e, portanto, também do valor da sociologia.

A oportunidade de, durante a fase de profissionalização, fazer a ponte entre as duas disciplinas maiores - sociologia e ciência política não foi aproveitada. A grande maioria dos representantes da sociologia política tem filiação institucional a uma das duas disciplinas e à respectiva sociedade científica. Ademais, a sociologia política na Alemanha continua baseada em duas culturas de pesquisa diferentes: na ciência política, por um lado, e na sociologia, por outro. A interdisciplinaridade existe, de qualquer modo, na cabeça de sociólogos políticos individuais, mas não através de fronteiras institucionais.

Katrin Möltgen - Doutora em Ciência Política pela Universidade de Münster e professora titular da Universidade de Ciências Sociais Aplicadas à Administração Pública e Privada da Renânia do Norte-Vestfália em Bielefeld e Colônia. $V^{k}$ katrin.moeltgen@fhoev.nrw.de

Malte Schophaus - Doutor em Sociologia pela Universidade de Bielefeld e professor associado da Universidade de Ciências Sociais Aplicadas à Administração Pública e Privada da Renânia do Norte-Vestfália em Bielefeld e Colônia. malte.schophaus@fhoev.nrw.de 
Sociologias, Porto Alegre, ano 17, no 38, jan/abr 2015, p. 64-91

\section{Referências}

1. ALEMANN, Ulrich von. Wem gehört die politische Soziologie? Die Brücke zwischen Politikwissenschaft und Soziologie, Soziologie, 27, 2, p. 5-16, 1998.

2. BACH, Maurizio. Die charismatischen Führungsdiktaturen. Drittes Reich und italienischer Faschismus im Vergleich ihrer Herrschaftsstrukturen. Baden-Baden: Nomos, 1990.

3. BACH, Maurizio. Denken Soziologen anders über Politik als Politikwissenschaftler? Zur Eigenständigkeit der Politischen Soziologie, Soziologie, 33, 2, p. 17-34, 2004.

4. BENZ, Arthur; DOSE, Nicolai (Hrsg.). Governance - Regieren in komplexen Regelsystemen. 2. Aufl. Wiesbaden: Verlag für Sozialwissenschaften, 2010.

5. BOGUMIL, Jörg; GROHS, Stephan; KUHLMANN, Sabine; OHM, Anna K.. Zehn Jahre neues Steuerungsmodell. Eine Bilanz kommunaler Verwaltungsmodernisierung. Berlin: Edition Sigma, 2007.

6. EBBIGHAUSEN, Rolf. Politische Soziologie. Zur Geschichte und Ortsbestimmung. Opladen: Westdeutscher Verlag, 1981.

7. ENDRUWEIT, Günter. Politische und apolitische Soziologie. Bemerkungen zu den speziellen Soziologien, im Anschluss an Ulrich von Alemanns Beitrag in Soziologie 2/98, Soziologie, 27, 4, 1998, p. 32-5.

8. FRITZ-VANNAHME, Joachim. Wozu heute noch Soziologie? Opladen: Leske; Budrich, 1996.

9. HITZLER, Ronald. Wissenschaft und Politik als Problem. Gegen die Zwangsetikettierung der Sektion "Politische Soziologie" - im Anschluss an Günter Endruweit, Soziologie, 2/99, p. 55-60, 1999.

10. HOLTKAMP, Lars; BOGUMIL, Jörg; KIßLER, Leo. Kooperative Demokratie Die Förderung von Bürgerengagement und Bürgerbeteiligung. Studien zur Demokratieforschung. Franfurt a.M.: Campus, 2006.

11. JOAS, Hans. Zwischen machtpolitischem Realismus und pazifistischer Utopie. Krieg und Frieden als Thema der soziologischen Theorie. Berliner Journal für Soziologie, Sonderheft 1, 1991, p. 59-71.

12. JOAS, Hans; KOHLIi, Martin. Der Zusammenbruch der DDR - Soziologische Analysen. Frankfurt a.M.: Suhrkamp, 1993.

13. KLENK, Tanja; NULLMEIER, Frank. Public Governance als Reformstrategie. Nr. 97. Düsseldorf: Edition der Hans-Böckler-Stiftung, 2004.

14. LEPSIUS, M. Rainer. The Development of Sociology in Germany after World War II (1945-68). International Journal of Sociology XIII: 3-88, 1983. 
Sociologias, Porto Alegre, ano 17, no 38, jan/abr 2015, p. 64-91

15. MEUSER, Michael. Politische Soziologie - Ortsbestimmungen und aktuelle Forschungsgebiete, Soziologie, 32, 1, 2003, p. 48-65.

16. NASSEHI, Armin / SCHROER, Markus. Einleitung. In A. Nassehi e M. Schroer (eds.), Der Begriff des Politischen. Sonderband 14, Soziale Welt. Baden-Baden: Nomos, 2003.

17. NEDELMANN, Birgitta. Die Wiederentdeckung des Politischen. Soziologische Revue, 17, 1994, p. 265-271.

18. NEDELMANN, Birgitta. Between National Socialism and Real Socialism: Political Sociology in the Federal Republic of Germany. Current Sociology, 45, 1997, p. 157-186.

19. OFFE, Klaus. Politische Herrschaft und Klassenstrukturen. Zur Analyse spätkapitalistischer Gesellschaftssysteme. In: G. Kress e D. Senghaas (Hrsg.), Politikwissenschaft: Eine Einführung in ihre Probleme. Frankfurt a.M.: Europäische Verlagsanstalt, 1969, 155-189.

20. SCHWAB-TRAPP, Michael. Kriegsdiskurse. Die Politische Kultur des Krieges im Wandel 1991-1999. Opladen: Leske; Budrich, 2002.

21. Sektion Politische Soziologie der DGS. Programmpapier Nr. 1 der Sektion Politische Soziologie der Deutschen Gesellschaft für Soziologie (DGS). Oktober 1994. Disponível em: http://www.politischesoziologie.eu/ Seiten/steiniv2/ benutzerdateien/Programmpapier-1-1994\%281\%29.pdf. Acesso em: 25.06.2014.

22. Sektion Politische Soziologie der DGS (2006). Programmpapier Nr. 2 der Sektion Politische Soziologie der Deutschen Gesellschaft für Soziologie (DGS). Februar 2006. Disponível em: http://www.politischesoziologie.eu/Seiten/ steiniv2/ benutzerdateien/Programmpapier\%20Nr_2-feb06\%282\%29.pdf. Acesso: 25.06.2014.

23. SOFSKY, Wolfgang. Die Ordnung des Terrors: Das Konzentrationslager. Frankfurt a.M.: Fischer, 1993.

24. STAMMER, Otto; WeINGART, Peter. Politische Soziologie. München: Juventa, 1972

25. TROTHA, Trutz von. Perspektiven der politischen Soziologie, Soziologie, 35 , 3, 2006, p. 283-302.

26. TROTHA, Trutz von. Soziologie der Politik: Akteure, Konflikte, Prozesse. In: G. Kneer e M. Schroer (eds.), Handbuch spezielle Soziologien. Wiesbaden: VS Verlag für Sozialwissenschaften, 2010.

Recebido em: 24/06/2014

Aceite Final: 07/07/2014 